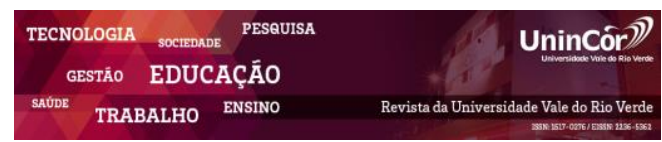

Revista da Universidade Vale do Rio Verde ISSN: 1517-0276 / EISSN: 2236-5362 v. $17 \mid$ n. 1 | Ano 2019

\section{RESÍDUOS DE FILTROS LUBRIFICANTES E OLUC (ÓLEO LUBRIFICANTE USADO E CONTAMINADO) EM AUTOMÓVEIS DA MARCA FIAT E A LOGÍSTICA REVERSA}

\section{RESUMO}

O artigo apresenta uma discussão a respeito dos resíduos gerados em manutenções de automóveis, com destaque para os filtros lubrificantes, que inclui-se a geração de alguns componentes como o OLUC, membranas filtrantes e peças metálicas. Objetivou-se quantificar estes resíduos provenientes da troca de filtros lubrificantesa partir dos registros de assistências técnicas de uma concessionária de veículos da marca FIAT, localizada em Goiânia, Goiás. A metodologia consistiu em levantamento do quantitativo sobre o recolhimento de OLUC coletadas na concessionária de automóveis no período de análise. Posteriormente, procedeu-se a decomposição dos filtros lubrificantes usados, dividindo-os em duas partes e possibilitando o escoamento do óleo lubrificante residual. A tabulação dos resultados foi realizada por Análise de Regressão, estatística mídias descritiva. Foi possível apresentar resultados quantificados, como também a logística reversa como alternativa viável à destinação dos resíduos gerados.

Palavras-chave: Filtros lubrificantes. Óleo lubrificante usado. Automóveis. Oluc. Logística Reversa.

\section{WASTE OF LUBRICATING FILTERS AND OLUC (USED AND CONTAMINATED LUBRICATING OIL) IN FIAT BRAND AUTOMOBILES AND REVERSE LOGISTICS}

\begin{abstract}
The article presents a discussion about the waste generated in car maintenance, especially the lubricating filters, which includes the generation of some components such as OLUC, filter membranes and metal parts. The objective was to quantify these residues from the exchange of lubricating filters from the records of technical assistance of a vehicle dealership of the brand FIAT, located in Goiânia, Goiás. The methodology consisted of a quantitative survey on the collection of OLUC collected at the automobile dealership in the period of analysis. Subsequently, the used lubricant filters were decomposed, dividing them into two parts and allowing the residual lubricating oil to flow. The tabulation of the results was performed by Regression Analysis, statistical descriptive media. It was possible to present quantified results, as well as the reverse logistics as a viable alternative to the destination of the generated residues.
\end{abstract}


Keywords: Lubricating filters. Used lubricating oil. Automobiles. Oluc. Reverse logistic.

Recebido em: XX/XX/XXXX - Aprovado em: XX/XX/XXXX - Disponibilizado em: XX/XX/XXXX

\section{INTRODUÇÂO}

Sabe-se que o setor automobilístico está entre os setores com maior capacidade poluidora, e, ao mesmo tempo, possui um grande potencial mitigador de seus impactos, seja por meio do reuso e remanufatura, como também pela reciclagem dos materiais, peças e componentes dos veículos produzidos. Esta área, ao decorrer das últimas décadas, vem implantando alternativas viáveis econômica e ambientalmente sustentáveis, de forma a reduzir seus impactos ambientais, otimizar a produção, além de se atentar a real necessidade em se gerenciar, principalmente, toda cadeia de geração dos resíduos sólidos durante o ciclo de vida útil do automóvel.

A crescente preocupação do poder público e da sociedade com as questões ambientais tem contribuído para a elaboração de leis, mudanças de hábitos e surgimento de novos procedimentos para a proteção ambiental em diversos setores da indústria brasileira, e o automobilístico está entre estes.

Assim, faz-se necessário um sistema produtivo, em todos os ramos industriais, que busque a sustentabilidade, que se ancora em três pilares: respeito ao meio ambiente, respeito às pessoas envolvidas e lucratividade (BRASIL, 2017).
Portanto, a preocupação referente à geração de resíduos no setor automobilístico não se resume apenas na fabricação e montagem dos mesmos. É necessário verificar todo o ciclo de vida do automóvel, desde sua fabricação até ao descarte final.

Para Miragaya (2013) este ciclo de vida do automóvel vai desde quando o mesmo é produzido pelo fabricante e colocado em uso pelo seu primeiro proprietário até o seu descarte final pelo último dono.

Assim, durante a vida útil do veículo automotor haverá geração de certo volume de resíduos. Algumas peças do veículo o acompanharão até o término do seu ciclo, no entretanto, outros componentes precisarão ser substituídos periodicamente, em função do seu desgaste ocasionado pelo uso.

Para Pasqualetto, Machado e Morais (2017), as intervenções mecânicas nos veículos automotores ocorrem pelas manutenções preventivas e corretivas, e geralmente se verificam substituições de componentes, que se tornam resíduos específicos.

Neste seguimento, Moraes (2015), alerta que:

O fabricante do automóvel preconiza substituições periódicas de componentes como filtros, correias, óleos lubrificantes, velas, mangueiras, cabos, fluídos, pastilhas, lonas de freios, pneus, válvulas, entre outros. 
Pode-se elencar vários itens de diversos subsistemas que formam o veículo, que também requerem trocas periódicas, tais como: direção, suspensão, freios, motorização, câmbio, semiárvores, iluminação, embreagem, forração ou tapeçaria, sistemas elétricos, acessórios e outros. Essas trocas ocorrem em função da quilometragem percorrida, tempo de uso, desgaste natural ou ainda por colisões. (MORAES, 2015, p.1).

Dentre os resíduos gerados nessas manutenções do automóvel estão os filtros lubrificantes, que inclui-se a geração de alguns componentes como o OLUC, membranas filtrantes, peças metálicas, entre outros que se tornam resíduos e que serão o foco deste estudo.

Em relação à logistica reversa desse tipo de resíduo, existe sim dispositivos legais que envolvem todas as etapas do ciclo do veículo automotor, desde a fabricação até o consumo. Porém, apenas o consumidor ou no máximo o varejista são quem normalmente arcam com os custos de descarte referente a destinação final dos resíduos sólidos gerados com a manutenção do autómovel (PASQUALETTO, MACHADO E MORAIS, 2017).

Conforme determina o artigo $30^{\circ}$ da Lei Federal $\mathrm{n}^{\mathrm{o}}$ 12305/2010, que dispõe sobre a Política Nacional de Resíduos Sólidos - PNRS, a responsabilidade sobre o gerenciamento e correta destinação destes resíduos deve ser compartilhada entre o fabricante, o distribuidor, o varejista e até mesmo o consumidor (BRASIL, 2010).

Neste sentido, a Resolução do Conselho Nacional de Meio Ambiente - CONAMA $n^{\circ}$ $362 / 2005$, trás em seu artigo $2^{\circ}$, inciso $\mathrm{V}$, dispõe que toda pessoa, seja física ou jurídica, que em decorrência de sua atividade exercida venha a gerar o OLUC possuirá a responsabilidade (artigo $\left.5^{\circ}\right)$ de recolher e efetuar o armazenamento temporário dos mesmos e destinar às empresas coletoras e especializadas no rerrefino, devidamente autorizadas pela Agência Nacional do Petróleo - ANP.

Portanto, no que diz respeito exclusivamente aos resíduos gerados durante a troca dos filtros lubrificantes, Chiconi (2017) salienta que os fabricantes de automóveis recomendam a troca de óleo lubrificante em duas situações: por tempo ou por quilometragem.

A FIAT, marca automobilística presente no Brasil, determina a troca de óleo a cada 15.000 quilômetros percorridos, podendo, entretanto, em condução severa de uso, a troca reduzir para 7.500 quilômetros (FIAT, 2014).

Objetivou-se neste trabalho quantificar os resíduos provenientes da troca de filtros lubrificantes, incluindo-se o OLUC residual, gerados em função das manutenções mecânicas realizadas em veículos automotores, a partir dos registros de assistências técnicas de uma concessionária de veículos da marca FIAT, localizada em Goiânia, Goiás.

\section{METODOLOGIA}

\subsection{Abordagem, objeto de estudo e escopo}

Para a confiabilidade do estudo foi realizada uma abordagem combinada, tanto qualitativa como quantitativa, de forma a explicar a relação entre a geração de OLUC e demais resíduos

Para coleta de dados foi selecionada uma concessionária de veículos automotores da marca FIAT, localizada na cidade de Goiânia, capital do 
Estado de Goiás, localizada na região CentroOeste do Brasil.

As informações tabuladas e estudadas quanto a relativa geração de OLUC ocorreu em um período de doze meses, entre 01 de junho de 2013 e 31 de maio de 2014.

\subsection{Etapas da pesquisa}

A pesquisa procedeu-se da seguinte maneira:

i) Primeiramente, realizou-se a coleta de dados sobre a quantidade de óleo lubrificantes trocados em manutenções realizadas na concessionária de veículos relacionada;

ii) Em seguida, foi determinado o quantitativo sobre o recolhimento de OLUC coletadas na concessionária de automóveis no período de análise, no qual foi possível verificar a geração de resíduos em cada filtro lubrificante usado, substituído no serviço de manutenção;

iii) Posteriormente, procedeu-se a decomposição dos filtros lubrificantes usados. O desmanche no filtro lubrificante foi realizado através de um pequeno torno mecânico, equipado com uma ferramenta de corte de aço. Após a fixação do filtro em um cabeçote, consistindo de três placas que posteriormente, entravam em movimento, uma ferramenta de corte avançava sobre o filtro efetuando uma cisão em sua carcaça metálica, dividindo-a em duas partes e possibilitando o escoamento do óleo lubrificante residual;

iv) Finalmente, a etapa de tabulação dos resultados por meio de Análise de Regressão, estatística mídias descritiva, para redação dos resultados obtidos.

\subsection{Variáveis da pesquisa}

i) Variáves relacionadas ao óleo lubrificante: óleo lubrificante (litros/mês.marca de veículo), filtro lubrificante (unidades /mês. marca de veículo) e óleo lubrificante (litros /Veículo.filtrolubrificante trocado), todos consumidos em cada troca de filtro realizada mensamente na concessionária, dentro do período de pesquisa. O consumo de óleo lubrificante por veículo foi obtido por meio da razão entre os dados de registros mensais de volumes consumidos de óleo combustível e quantidade de filtros lubrificantes dispendidos. $\mathrm{O}$ consumo de óleo lubrificante (litros/veículo) foi determinada pela Equação 1:

Equação 1: Consumo de óleo combustível por veículo

$$
L O=\frac{\sum_{i=1}^{n} x i}{\sum_{i=1}^{n} y i}
$$

Onde:

L o = Quantidade média de óleo consumido por veículo em cada troca de óleo (litros /unidade); xi $=$ Quantidade de óleo lubrificante consumido em cada veículo, durante o período considerado (litros);

yi = Quantidade de filtros lubrificantes utilizados durante o período considerado (unidades). Em Cada veículo foi consumido apenas um filtro de óleo;

$\mathrm{n}=$ Número de períodos (meses) considerados na Amostra

ii) Variáveis relacionadas à análise do filtro lubrificante: OLUC (litros/filtro), metálico resíduo (kg /filtro), borrachas ( $\mathrm{kg} /$ filtro), plásticos (kg/filtro) e membrana filtrante (kg/filtro); 
2.4 Dados de inventário e premissas

Ressalta-se que devido aos custos relacionados com o processo de decomposição dos filtros lubrificantes usados, a análise dos resíduos gerados por esses produtos foi baseada em amostragem. O cálculo das amostras foi determinada a partir do quantitativo de veículos, uma vez que foi considerado que cada veículo recebeu, para trabalhos de manutenção na concessionária, uma troca de óleo lubrificante. Nesta etapa, foram investigados 354 filtros de lubrificantes em veículos da marca FIAT.

\section{RESULTADOS E DISCUSSÕES}

3.1 Filtro lubrificante, OLUC e instrumentos legais para destinação correta

O filtro lubrificante é um conjunto formado por tampa, caneca, válvulas e juntas de vedação e tem a função de filtrar as impurezas do óleo, que circula pelo meio filtrante impulsionado pela pressão da bomba de óleo, que é ligada ao movimento de rotação do motor (MORAES, 2015). Ver Figura 1.

Figura 1 - Esquema apresentando componentes do filtro de óleo.

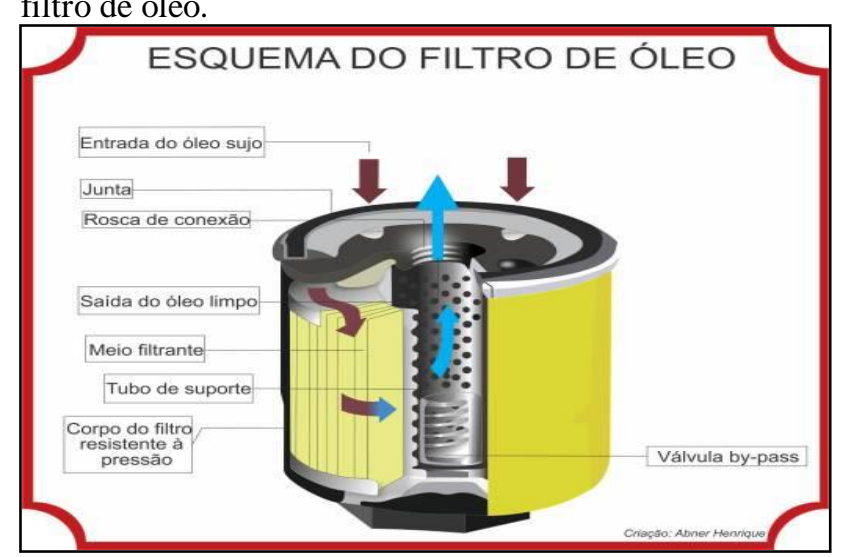

Fonte: Abner Henrique, 2018.
Após o uso, o filtro lubrificante terá em seu interior componentes contaminados por derivados do petróleo. Portanto, de acordo com a Associação Brasileira de Normas Técnicas ABNT, em sua Norma Brasileira NBR10.004/2004, estes filtros usados de óleo lubrificante automotivo podem ser classificados na classe I - Perigosos.

Acontece que boa parte dessas empresas onde se realizam a troca do filtro lubrificante, o consideram, após usados, como sucata metálica e não fazem a destinação correta. No entanto, vale ressaltar que a membrana filtrante deste componente retém óleo, sendo um potencial poluidor, caso não seja destinado adequadamente. Atualmente, já é possível cortar estes filtros, utilizando-se equipamentos específicos, e assim, após a retirada da membrana filtrante e OLUC residual, a carcaça metálica e demais componentes podem ser destinados a reciclagem e/ou coprocessamento adequados.

Salienta-se que a coleta e destinação correta destes resíduos podem ser efetuadas por empresas autorizadas pela Agência Nacional do Petróleo - ANP. Porém, no cenário nacional é verificado uma porcentagem baixa em relação ao recolhimento do OLUC (ANP, 2017).

No Brasil, essa destinação correta do OLUC é prevista por um conjunto de instrumentos legais, como:

- Lei Federal no 12.305/2010 - Política Nacional de Resíduos Sólidos;

- Resoluções do CONAMA no 362/2005 e $n^{\circ}$ 450/2012; 
- Portaria do Ministério de Meio Ambiente MMA n ${ }^{\circ}$ 31/2007, que institui o Grupo de Monitoramento Permanente;

- Portaria Interministerial do Ministério de Meio Ambiente - MMA e Ministério de Minas e Energia - MME, n 464/2007, que estabelece diretrizes para o recolhimento, coleta e destinação dos óleos usados e contaminados, determinando percentuais mínimos de coleta, a serem atendidos pelos produtores e importadores de lubrificantes acabados, por região e no Brasil.

Portanto, a não obediência as normativas do setor condicionam sujeição a lei de crimes ambientais Lei 9605/98 e às penalidades impostas.

Hsu e Liu (2011) alertam que o óleo lubrificante usado não deve ser descartado aleatoriamente, devido à presença de agentes nocivos ao meio ambiente.

O descarte dos filtros usados sem a devida remoção prévia do óleo contido nele, não apenas desperdiça recursos naturais, como o caso do aço, como também se torna um potencial contaminante para o meio ambiente, devido à possibilidade de vazamento deste OLUC residual (SINDIRREFINO, 2018).

Portanto, a realidade em solo brasileiro para o OLUC é que seu único destino seja o rerrefino e quaisquer outras aplicações são consideradas ilegais e sujeitas às penalidades previstas na legislação.

A responsabilidade pela gestão dos resíduos neste setor não é apenas do concessionário. A legislação nacional assevera que tanto os fabricantes, os distribuidores e até mesmo o consumidor devam destinar adequadamente os resíduos gerados em todo o ciclo do automóvel.

\section{2 Óleo lubrificante e filtros consumidos}

Conforme apresentado na metodologia, foram investigados 354 filtros de lubrificantes em veículos da marca FIAT, trocados em conssecionária localizada em Goiânia, Goiás.

A FIAT (2014) cita em seu livreto de garantia do veículo da família Punto:

Atenção: o óleo lubrificante do motor degrada-se por quilometragem ou pelo tempo. Portanto, é imprescindível sua substituição de acordo com o Manual de Uso e Manutenção, respeitados os prazos de validade e/ou quilometragem [...] (FIAT, 2014, p.34).

Esta fabricante, portanto, preconiza a troca de óleo a cada 15000 quilômetros percorridos. Porém, em condução severa a troca reduz para 7500 quilômetros.

Na Tabela 1 são apresentados os dados de óleo novo utilizado e o óleo residual resultante da troca realizada nos veículos.

Percebe-se que a diferença média entre a entrada de óleo lubrificante novo e saída de óleo residual, o chamado OLUC, foi de $-18,09 \%$. Ou seja, há perdas durante o funcionamento do motor, nos filtros e possibilidades de desperdícios na coleta do OLUC, justificando a redução entre a entrada e a saída do óleo. Importante ressaltar que nem todo o óleo lubrificante consumido é convertido em OLUC, devido as perdas no processo de troca ou mesmo consumo (DUQUE, 2017). 
Tabela 1 - Consumo de óleo lubrificante e recolhimento de OLUC em veículos da marca FIAT entre 2013 e 2014.

\begin{tabular}{llllr}
\hline & & & Mês/ano & \\
\cline { 2 - 5 } & Óleo & OLUC & (L) & Variação \\
\hline jun./13 & 1214 & 1100 & $-10,36$ \\
jul./13 & 1205 & 600 & $-100,83$ \\
ago./13 & 1294 & 1500 & 13,73 \\
set./13 & 1293 & 1100 & $-17,55$ \\
out./13 & 1201 & 1200 & $-0,08$ \\
nov./13 & 1267 & 1200 & $-5,58$ \\
dez./13 & 1419 & 1000 & $-41,90$ \\
jan./14 & 1367 & 1000 & $-36,70$ \\
fev./14 & 1326 & 1000 & $-32,60$ \\
mar./14 & 1163 & 1000 & $-16,30$ \\
abr./14 & 1163 & 1100 & $-5,73$ \\
mai/14 & 1204 & 1000 & $-20,40$ \\
\hline Total & 15116 & 12800 & $-18,09$ \\
\hline
\end{tabular}

Fonte: Autores, 2018.

Salienta-se que abatendo-se as reduções proporcionadas, ainda há considerável volume de OLUC que deve ser apropriadamente destinado, Na tabela 2 são apresentados os registros conforme recomenda a legislação vigente. mensais de serviços realizados em veículos na concessionária da marca FIAT, em que ocorreram trocas de óleo lubrificante e filtro lubrificante.

Tabela 2 - Quantidade de óleo lubrificante e filtros consumidos na concessionária da marca FIAT

\begin{tabular}{lrr}
\hline Período & $\begin{array}{r}\text { Óleo lubrificante } \\
\text { consumido (L) }\end{array}$ & Filtro lubrificante consumido (unidades) \\
\hline jun./13 & 1214 & 362 \\
jul./13 & 1205 & 355 \\
ago./13 & 1294 & 376 \\
set./13 & 1293 & 383 \\
out./13 & 1201 & 352 \\
nov./13 & 1267 & 373 \\
dez./13 & 1419 & 412 \\
jan./14 & 1367 & 400 \\
fev./14 & 1326 & 386 \\
mar./14 & 1163 & 345 \\
abr./14 & 1163 & 337 \\
mai/14 & 1204 & 341 \\
\hline Total & $\mathbf{1 5 1 1 6}$ & $\mathbf{4 4 2 2}$ \\
\hline
\end{tabular}

Fonte: Autores, 2018.

Considerando a razão entre o somatório de óleo lubrificante consumido durante o período 
verificado e a quantidade de filtros lubrificantes trocados nos serviços, equivalente à quantidade de automóveis que receberam serviços de manutenção, obteve-se 3,42 litros/filtro.

Após determinar o consumo de óleo lubrificante por veículo da marca Fiat foi realizada uma análise de regressão, considerando as variáveis consumo de óleo lubrificante e óleo consumido, respectivamente, como variáveis independente e dependente. do coeficiente de determinação, igual a 95,91\%, indicam uma elevada capacidade da equação y = 3,3621x - 20,743, em expressar a relação de dependência existente entre as variáveis consideradas na análise. A Figura 2 apresenta os resultados obtidos na regressão.

Fica evidente a maior demanda entre dezembro e janeiro, período de revisões para viagens de festas de natal e virada de ano, associadas às férias de grande parte da população, especialmente escolares.

Os resultados obtidos em relação ao valor

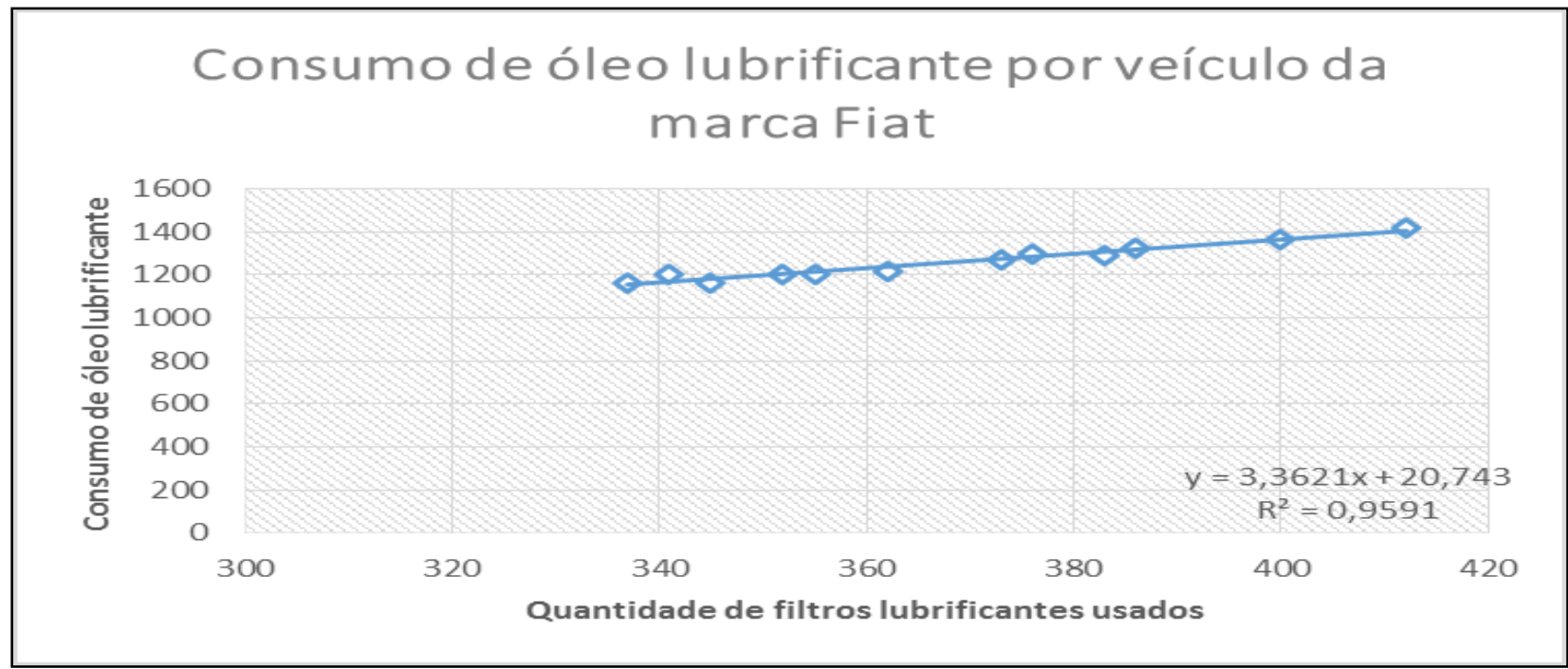

Figura 2 - Relação entre consumo de óleo lubrificante e quantidade de filtros para veículo da marca Fiat.

Fonte: Autores, 2018.

\subsection{Decomposição do filtro lubrificante usado}

A partir do quantitativo dos componentes encontrados no interior dos filtros lubrificantes usados foi possível realizar análise da sua decomposição ou desmanche, conforme apresentado a seguir. A finalidade desta etapa consiste em apresentar o reaproveitamento dos materiais e a destinação adequada do OLUC residual, metálicos, plásticos, membranas filtrantes e borrachas, os quais possuem processos de destinação distintos. 
O procedimento de decomposição ou o desmonte dos filtros lubrificantes permite a retirada dos diversos materiais que o formavam e separá-los, conforme a sua natureza, possibilita a correta destinação de suas partes.

A não separação torna todo o conjunto em resíduo perigoso devido à impregnação do óleo lubrificante. Cerra et al. (2014) citam que a busca pela redução de resíduos deve ser perseguida, tanto no âmbito da concepção do produto como no pós-consumo.
$\mathrm{Na}$ fase de desmanche do filtro lubrificante retirou-se os demais materiais internos (capa, tuchos, válvulas e OLUC residual), com o intuito de conhecer o peso de cada componente (Figura 3). As capas metálicas, que foram submetidas ao corte, ficaram prontas para serem encaminhadas à reciclagem.

Figura 3 - Componentes metálicos e membranas filtrantes dos filtros usados, desmanchados e separados
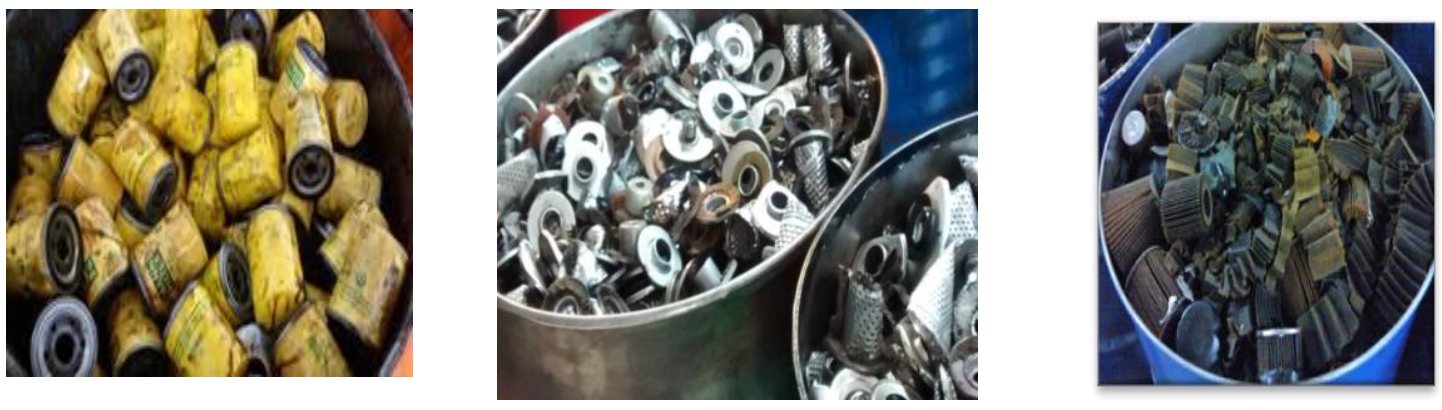

Fonte: Autores, 2018.

A membrana filtrante é o único componente do filtro lubrificante usado que não permite uma reciclagem direta, devido o fato de estar impregnada com derivados do petróleo. Entretanto, o coprocessamento em fornos de cimenteiras se apresenta como a correta destinação para a mesma, que se consolida como alternativa na redução de passivo ambiental de vários processos produtivos, transformando $\mathbf{o}$ resíduo em matéria-prima ou em combustível alternativo na produção do cimento (SELLITTO et al. 2013).

Após o corte no filtro lubrificante usado, o OLUC residual é escoado e segregado em reservatório específico para ser destinado ao rerrefino.
As resoluções do CONAMA no 362/2005 e $n^{\circ} 450 / 2012$ dispõem sobre o rerrefino como destino obrigatório do OLUC.

O rerrefino é um processo de reaproveitamento do óleo lubrificante básico, que corresponde de $80 \%$ a $85 \%$ do OLUC (MORAES, 2015).

De acordo Tamada et al. (2012), com O OLUC oferece periculosidade maior, tendo em vista, que carrega uma carga de componentes nocivos à saúde como dioxinas, ácidos orgânicos, cetonas, hidrocarbonetos policíclicos aromáticos, chumbo, cádmio, cromo e arsênio.

Na Tabela 3, são apresentadas as quantidades unitárias de resíduos geradas em cada 
filtro analisado e o quantitativo residual

produzido, considerando as amostras analisadas.

Tabela 3 - Síntese da geração de resíduos nos filtros lubrificantes de veículos.

\begin{tabular}{|c|c|c|}
\hline \multirow[b]{3}{*}{ Resíduos gerados } & \multicolumn{2}{|r|}{ Veículos } \\
\hline & \multicolumn{2}{|r|}{ Fiat } \\
\hline & $\begin{array}{ll}\begin{array}{l}\text { Quant. } \\
(\mathrm{kg} / \text { filtro })\end{array} & \text { Unitária } \\
\end{array}$ & Quant. Amostral (kg) \\
\hline OLUC & 0,0491 & 17,38 \\
\hline Materiais metálicos & 0,1886 & 66,78 \\
\hline Borracha & 0,048 & 1,698 \\
\hline Plástico & 0,0036 & 1,278 \\
\hline Membrana filtrante & 0,06268 & 22,189 \\
\hline
\end{tabular}

Fonte: Os autores, 2018.

Conforme verificado, a maior quantidade residual gerada corresponde aos materiais plásticos, que poderão ser encaminhados a reciclagem. O OLUC, que é a segunda maior quantidade gerada, sabe-se que deve passar pelo rerrefino.

\section{Conforme ANFAVEA}

(2014), considerando as possibilidades de reciclagem dos componentes do filtro lubrificante, especialmente o rerrefino do óleo residual, é notório o potencial de redução de risco ambiental se adotadas as medidas de correta destinação e reaproveitamento.

3.4 Logística reversa dos resíduos de filtros lubrificantes de veículos automotores

Figura 4 - Fluxo logístico de resíduos de óleo usado

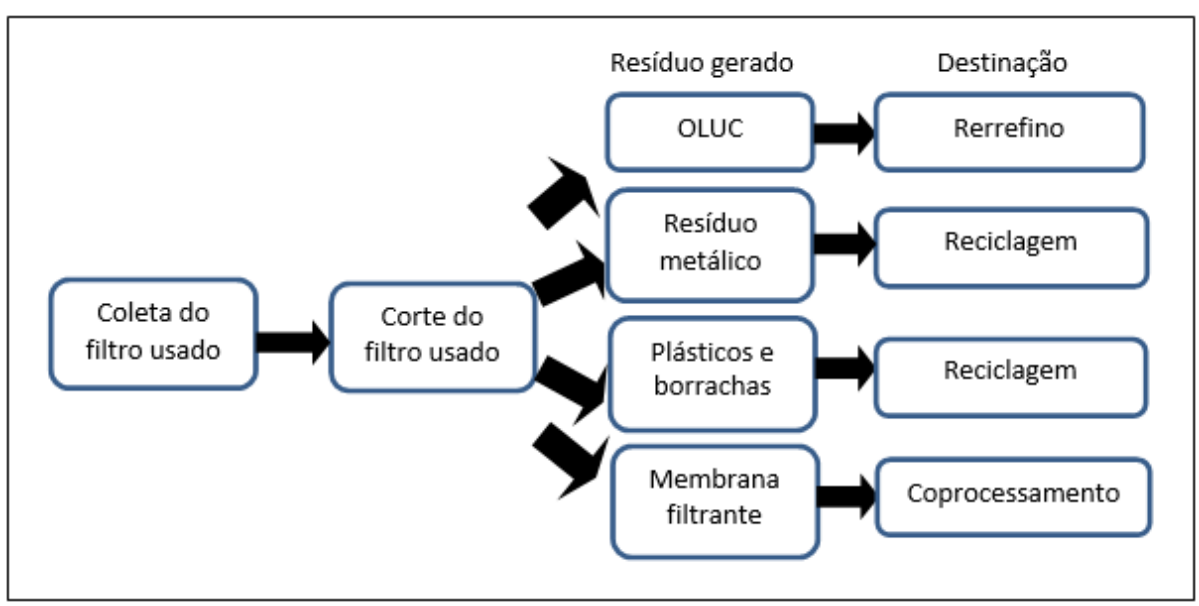

Fonte: Adaptado de Moraes (2015) 
Conforme apresentado na Figura 4, é sintetizado o processo de reciclagem do filtro lubrificante usado. Verifica-se nesta que existem diferentes destinações para os materiais obtidos nos desmanches dos filtros. O OLUC é encaminhado ao processo de rerrefino, os resíduos metálicos são reciclados e a membrana filtrante é encaminhado ao coprocessamento.

O processo de logística reversa inicia-se na coleta dos filtros lubrificantes usados nas próprias concessionárias, e então, após a operação de corte, na organização de processamento de produtos usados.

O corte do filtro gera diversos produtos, como o OLUC, resíduos metálicos e membranas filtrantes. Cada resíduo, devido suas características, passa por um processo distinto de reprocessamento: o OLUC segue para uma operação de rerrefino, o resíduo metálico é reciclado e a membrana é coprocessada.

Miguez (2010) ressalta que logística reversa tem impacto direto na melhoria do ambiente, pois reduz a quantidade de materiais perigosos que antes iam para os aterros e corpos hídricos a céu aberto, diminuindo riscos de contaminação.

Outro efeito positivo da logística reversa no meio ambiente é o recolhimento e reaproveitamento de produtos, fazendo com que menos matéria-prima in natura seja utilizada, poupando recursos minerais e energéticos (MORAES, 2015).

Mas, no Brasil, ainda é preciso melhorar muito essa cadeia da logística reversa dos resíduos considerados perigosos, principalmente do setor automobilístico.
Aliado a logística reversa dos componentes do filtro de óleo usado, De Benedetto e Klemes (2009) citam que a análise de ciclo de vida na gestão de produtos em uma perspectiva humanizada, é benéfica à sociedade, pois, a redução dos impactos ambientais na produção melhora a qualidade de vida.

\section{CONSIDERAÇÕES FINAIS}

A partir deste estudo, no qual se buscou estimar o quantitativo dos resíduos automotivos de filtros lubrificantes, incluindo o OLUC residual, produzidos em função da execução das atividades de manutenção mecânica em veículos automotores a partir dos registros de assistências técnicas de concessionária de veículos da marca FIAT, foi possível apresentar como os resultados quantificados, como também a logística reversa como alternativa viável à destinação dos resíduos gerados.

Entretanto, percebe-se para que a coleta do OLUC seja possível é necessário que os coletores remunerem os revendedores, que nesse caso são os postos de gasolina, concessionárias de automotores, oficinas mecânicas, entre outros, pois somente dessa forma é que haverá segregação sem mistura em água e outros contaminantes.

Pasqualetto, Machado e Morais (2017) afirmam que o OLUC, após passar pelo processo de rerrefino, se transforma no óleo lubrificante básico rerrefinado e possui valor de mercado. É necessário explorar esse valor agregado quando o mesmo é resíduo.

A tendência é que se consolide uma gestão eficaz no gerenciamento dos resíduos 
produzidos, com muito mais rigor do que os próprios órgãos ambientais fiscalizadores, tendo em vista, os mecanismos existentes de bonificação ao concessionário por cumprimento de metas, como o índice de qualidade de atendimento, desempenho de vendas, índice de qualidade de serviços, que implicará em uma maior ou menor taxa de mão de obra por serviços prestados às montadoras em intervenções em garantia, ou Hold back $^{l}$, entre outros mecanismos de premiação.

Dentre os resíduos produzidos pelos veículos nas trocas de óleo lubrificante, como já comentando, tem-se o OLUC, que já possui um processo de destinação bem definido pelo Ministério do Meio Ambiente e Ministério de Minas e Energia, com criação de normas e portarias de destinação, com estrutura logística robusta e com ampla cobertura no território brasileiro. $\mathrm{O}$ rerrefino, conhecido como $\mathrm{O}$ processo de recuperação do óleo básico do OLUC, se constitui na única destinação legalmente aceita do OLUC no Brasil.

Percebe-se a necessidade de inovação nos equipamentos e técnicas voltados para o desmonte de filtros lubrificantes que podem auxiliar, por exemplo, os designers de autopeças na criação de produtos com maior facilidade de desmonte, possibilitando dessa forma, a destinação total dos materiais residuais. Levando em consideração este aspecto observado na pesquisa, destaca-se a presença da membrana filtrante que após a sua remoção, torna os componentes metálicos com

${ }^{1}$ Hold back: Percentual dos valores de autopeças e veículos retidos em algumas montadoras a favor do concessionário a ser devolvido em situações e datas predeterminadas. elevado grau de pureza e com reduzidas escórias permitindo reciclagem.

Salienta-se também a necessidade de aprimorar a legislação relativa à estes resíduos e seu gerenciamento, de forma a contribuir para a construção de políticas para implantação de uma logística reversa eficiente, voltada para o setor automobilístico.

É importante destacar a urgente necessidade de modelos sustentáveis definidos para o segmento automotivo, trazendo a luz informações importante sobre a geração e destinação de materiais considerados perigosos e que oferecem danos ao meio ambiente.

\section{REFERÊNCIAS}

ABNT - ASSOCIAÇÃO BRASILEIRA DE NORMAS TÉCNICAS. Norma Brasileira - NBR $n^{\circ}$ 004/2004.

ANP - AGÊNCIA NACIONAL DE PETRÓLEO. Empresas autorizadas a exercer a atividade de coletores de Óleo Lubrificante Usado e Contaminado - OLUC para o rerrefino. Disponível em: http://www.anp.gov.br/?id=670. Acesso em: $22 \mathrm{de}$ nov. De 2017.

ANFAVEA - ASSOCIAÇÃO NACIONAL DOS FABRICANTES DE VEÍCULOS AUTOMOTORES. Brazil automotive Guide 2014: guia setorial da indústria automotiva brasileira, 2014.

BRASIL, A. Os três pilares da sustentabilidade: como o desenvolvimento econômico pode contribuir para os negócios, a natureza e a sociedade. Jornal Estadão. On-line: Blog Ecoando: Práticas empresarias sustentáveis. 2017. Disponível em: http://economia.estadao.com.br/blogs/ecoando/ostres-pilares-da-sustentabilidade-como-odesenvolvimento-economico-pode-contribuir-para-osnegocios-a-natureza-e-a-sociedade/. Acesso em: $15 \mathrm{de}$ fev. de 2018.

BRASIL. Lei n. 9.605, de 12 de fevereiro de 1998. Dispõe sobre as sanções penais e administrativas derivadas de condutas e atividades lesivas ao meio ambiente, e dá outras providências. 
BRASIL. Lei n. 12.305, de 2 de agosto de 2010. Institui a Política Nacional de Resíduos Sólidos; altera a Lei n. 9.605, de 12 de fevereiro de 1998, e dá outras providências.

CERRA, A. L.; MAIA, J. L.; ALVES FILHO, A. G.; NOGUEIRA, E. Cadeias de suprimentos de montadoras dos setores automobilísticos e de linha branca - Uma análise comparativa por meio de estudos de caso. Gest. Prod., São Carlos, v. 21, n. 3, p. $635-647$, p. 2014.

CHICONI, N. Troca de óleo. Revista Quatro Rodas, ed. Novembro, 2017.

CONAMA - CONSELHO NACIONAL DE MEIO AMBIENTE. Resoluções n] 362/2005 e no 450/2012, disponível em www.mma.gov.br, Brasília-DF.

DE BENEDETTO, L.; KLEMES, J. The Environmental performance Strategy $M$. an integrated LCA approach to support the strategy decision-making process. Journal of Clean Production, v. 17, p. 900-906, 2009.

DUQUE, S. O consumo de óleo lubrificante no mercado brasileiro. Revista Mercado Automotivo, ed. 220, abril de 2013. Disponível http://www.revistamercado automotivo.com.br/Oconsumo-de-oleo-lubrificante-\%20\%20no-mercadoautomotivo-brasileiro/219/r/. Acesso. 10 de junho de 2017.

FIAT AUTOMÓVEIS S/A. Manual de uso e manutenção família Palio. Betim, Fiat: 2014. p. 7.

HENRIQUE, ABNER. Esquema do filtro de óleo. Figura. Site: Oficina Brasil. Ano: 2018.

HSU, Y. L.; LIU, C. C. Evaluation and selection of regeneration waste lubricating oil technology. Environmental Monitoring and Assessment, v. 176, p. 197-212, 2011.

MIGUEZ, E.C. Logística reversa como solução para o problema do lixo eletrônico: benefícios ambientais e financeiros. Rio de Janeiro: Qualitymark, 2010.

MIRAGAYA, F. Ciclo de vida de um carro: lançamento, reestilização e séries até a despedida silenciosa. Revista Extra. ed. Setembro. 2013.

MORAES, J. Logística reversa de óleo lubrificante usado e contaminado - oluc em concessionárias de automóveis de Goiás. Dissertação. Mestrado em Engenharia de Produção e Sistemas. PUC Goiás. $2015 . \quad$ Disponível em: http://tede2.pucgoias.edu.br:8080/bitstream/tede/2488 /1/JUAREZ\%20DE\%20MORAIS.pdf. Acesso em 18 de nov. de 2017.
PASQUALETTO, A.; MACHADO, R. L.; MORAIS, J. DE . Estimativa dos resíduos de óleos lubrificantes e de componentes de filtros lubrificantes da frota e veículos goiana e brasileira. Engenharia Ambiental Espírito Santo do Pinhal , v. 14, n. 2, p. 21-43, jul./dez. 2017. Disponível em: http://ferramentas.unipinhal.edu.br/engenhariaambie ntal/include/getdoc.php?id=3367\&article=1442\&mod e=pdf. Acesso em 09 de fev. de 2018.

SELLITTO, M. A.; KADEL JR, N.; MIRIAN, B.: PEREIRA, G. M.; DOMINGUES, J. Coprocessamento de cascas de arroz e pneus e inservíveis e logística reversa na fabricação de cimento. Ambiente e Sociedade, v. XVI, n. 1, p. 141162, 2013.

\begin{tabular}{lrrrr}
\multicolumn{2}{l}{ SINDIRREFINO - } & SINDICATO NACIONAL DA \\
INDÚSTRIA & DO & RERREFINO & DE & ÓLEOS \\
MINERAIS. & Disponível & & em:
\end{tabular} <http://www.sindirrefino.org.br/>. Acesso em: $27 \mathrm{fev}$. 2018.

TAMADA, I. S.; LOPES, P. R. M.; MONTAGNOLLI, R. N.; BIDOIA, E. D. Biodegradadion and Toxicological Evaluation of Lubricant Oils. Brazilian Archives of Biology and Technology, v. 55, n. 6 p. 951-956, 2012.

\section{Ricardo Luiz Machado}

Engenheiro civil (UFG). Engenheiro de produção (UFSC). Doutor em Engenharia de Produção (UFSC). Docente na Pontifícia Universidade Católica de Goiás (PUC Goiás).

\section{Antônio Pasqualetto}

Engenheiro Agrônomo (UFSM). Doutor em Fitotecnia (UFV). Docente na PUC Goiás. Coordenador do programa de Mestrado em Desenvolvimento e Planejamento Territorial pela PUC Goiás.

\begin{tabular}{l}
\hline Juarez de Morais \\
Engenheiro de produção (PUC Goiás). Mestre em \\
Engenharia de Produção e Sistemas (PUC Goiás). \\
\hline
\end{tabular}

Wanessa Silva Rocha
Engenheira ambiental (PUC Goiás). Mestranda em
Desenvolvimento e Planejamento Territorial (PUC
Goiás).

